\title{
Direct Determination of $p$-Hydroxymethamphetamine Glucuronide in Human Urine by High-Performance Liquid Chromatography
}

\author{
Rika NaKajima, ${ }^{*, a}$ Muneo Morishita, ${ }^{b}$ Sadakazu Aiso, ${ }^{a}$ and Takehiko Yajima ${ }^{b}$ \\ ${ }^{a}$ School of Medicine, Keio University; 35 Shinanomachi, Shinjuku-ku, Tokyo 160-8582, Japan: and ${ }^{b}$ Faculty of \\ Pharmaceutical Sciences, Toho University; 2-2-1 Miyama, Funabashi, Chiba 274-8510, Japan.
}

Received October 24, 2005; accepted December 15, 2005

High-performance liquid chromatography (HPLC) with UV detection for the simultaneous determination of the free form of $p$-hydroxymethamphetamine ( $p$-OHMA) and its metabolite, glucuronide ( $p$-OHMAG) was accomplished for the first time. We achieved this by employing 1) an ion pair reagent for retention of sample to a solid-phase extraction (SPE) cartridge, Sep-Pak ${ }^{\circledR}$ Light C18 and 2) a simple two-step stepwise elution technique for subsequent ion pair RP-HPLC. The proposed method was optimized for resolution of $p$-OHMAG, $p$-OHMA and MA. The method was successfully applied to urine samples collected from MA abusers.

Key words $p$-hydroxymethamphetamine glucuronide; ion pair reagent; solid-phase extraction; HPLC; urine sample

Drug abuse has recently become a serious worldwide problem and is increasing rapidly. Illicit drugs are stimulants, marijuana, cocaine, heroin and tranquilizers, among which methamphetamine (MA) is the most frequently abused drug in Japan. Arrests for violation of the Stimulant Drug Control Law are now on the verge of 20000/year. MA addiction is evidenced by the detection of unchanged MA as well as metabolite amphetamine (AP), thus MA analysis in urine samples has been employed routinely as a standard screening test using thin layer chromatography (TLC), ${ }^{1}$ followed by gas chromatography/mass spectrometry $(\mathrm{GC} / \mathrm{MS}){ }^{2}{ }^{2} \mathrm{MA}$ is metabolized either by hydroxylation of the aromatic ring or demethylation of the side chain. It has been reported that the metabolites of MA in urine were excreted as the unchanged $(18-27 \%)$, free and conjugated forms of $p$-hydroxymethamphetamine ( $p$-OHMA; $14-16 \%)$ and AP $(2-3 \%)$ (Fig. 1). ${ }^{3)}$ It has been reported in the literature that the analysis of conjugated forms of $p$-OHMA in the urine samples of MA abusers used to be carried out by comparing the ratios of free $p$-OHMA to total $p$-OHMA before and after hydrolysis with $\beta$-glucuronidase or $\mathrm{HCl}$ treatment. ${ }^{4-8)}$ In the present paper, we describe the development and optimization of the method for the direct determination of intact $p$-OHMA glucuronide ( $p$-OHMAG). Even in a case where the concentration of AP present in the urine is too low to be determined, it has been reported that the levels of $p$-OHMA and its conjugated form excreted in the urine were much higher than AP. We are thus convinced that a simultaneous determination of $p$-OHMAG,
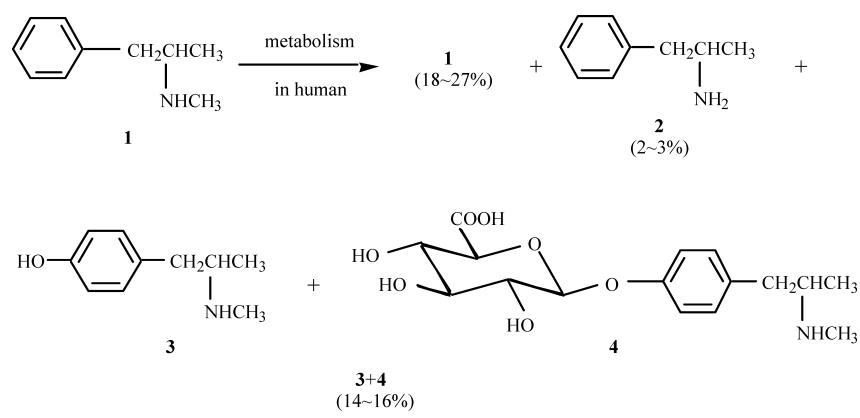

Fig. 1. The Metabolic Pathway for Methamphetamine (MA) in the Human Body

1. MA, 2. AP, 3. p-OHMA, 4. $p$-OHMAG
$p$-OHMA and MA in the urine of MA abusers could be unambiguous evidence of the ingestion of MA.

\section{Experimental}

Materials and Reagents $p$-Hydroxymethamphetamine glucuronide ( $p$ OHMAG) was synthesized from 4-hydroxyphenylacetic acid methyl ester according to the method developed in our laboratory. ${ }^{9)}$ Pholedrine, $p$-hydroxymethamphetamine ( $p$-OHMA) and methamphetamine (MA) hydrochloride were obtained from Sigma (St. Louis, MO, U.S.A.) and Dainippon Pharmaceutical (Osaka, Japan), respectively (Fig. 1). Sodium 1-dodecanesulfonate (ion pair grade) was purchased from Tokyo Kasei Kogyo (Tokyo, Japan). Methanol and acetonitrile were of HPLC grade, and all other reagents were of analytical grade.

Standard solutions: the concentrations of a standard solution were set in the vicinity of the limits of quantification (LOQ). Stock solutions were prepared by dissolving appropriate amounts of $p$-OHMAG, $p$-OHMA and MA in distilled water and were kept frozen until use, then diluted appropriately prior to use.

Distilled and deionized water prepared with Elix (Millipore, Tokyo) was used throughout this investigation.

Sep-Pak ${ }^{\circledR}$ Light C18 cartridges (reversed-phase monofunctional silane, $130 \mathrm{mg}$ ) were obtained from Waters Corp. (Milford, MA, U.S.A.).

A drug free urine sample collected from a healthy subject in our laboratory was used to make blank and spiked urine samples containing standard solutions. The urine samples of MA abusers were obtained from autopsy cases. These samples had previously been analyzed for the presence of amphetamines by Triage ${ }^{\circledR}$ immunoassay method and kept frozen at $-40^{\circ} \mathrm{C}$ until analysis.

Apparatus and Conditions The HPLC system consisted of an LC$10 \mathrm{AT}_{\mathrm{VP}}$ HPLC pump (Shimadzu, Kyoto, Japan), a model 7125 injector with a $20 \mu \mathrm{l}$ sample loop (Rheodyne, Cotati, CA, U.S.A.), an analytical column ( $150 \times 4.6 \mathrm{~mm}$ i.d., $5 \mu \mathrm{m}$ particle size: Inertsil ODS-3, GL Science, Tokyo) connected to a guard column $(50 \times 4.6 \mathrm{~mm}$ i.d., $5 \mu \mathrm{m}$ particle size: Inertsil ODS-3), a SPD-10A UV-VIS detector (Shimadzu), set at $220 \mathrm{~nm}$, and a CR6A recorder (Shimadzu).

The separation was carried out by a stepwise elution with the following two solutions: solution A, $10 \mathrm{~mm}$ phosphoric acid-acetonitrile-isopropyl alcohol (48:13:3) containing $5 \mathrm{~mm}$ sodium 1-dodecanesulfonate as ion pair reagent and solution $\mathrm{B}, 10 \mathrm{~mm}$ phosphoric acid-acetonitrile-isopropyl alcohol (32:13:3, v/v/v) containing $5 \mathrm{~mm}$ sodium 1-dodecanesulfonate.

The flow-rate of the mobile phase was set at $1.0 \mathrm{ml} / \mathrm{min}$ at room temperature and the elution was programmed as follows: $100 \% \mathrm{~A}$ for $0-25 \mathrm{~min}$ and $100 \%$ B after $25 \mathrm{~min}$.

Pretreatment of Urine Samples The urine sample $(0.5 \mathrm{ml})$ was mixed with $0.1 \mathrm{ml}$ of $2.5 \mathrm{~mm}$ sodium 1-dodecanesulfonate, and then applied onto a solid-phase extraction cartridge, Sep-Pak ${ }^{\circledR}$ Light C18, which was prewashed successively with $1.0 \mathrm{ml}$ of methanol and $2.0 \mathrm{ml}$ of $50 \mathrm{~mm}$ sodium dihydrogenphosphate adjusted to $\mathrm{pH} 7.0$ with sodium hydroxide.

The cartridge was rinsed with $0.5 \mathrm{ml}$ of $8 \%$ methanol in $0.2 \mathrm{M}$ carbonate buffer $(\mathrm{pH} 11.0)$ twice and with $0.5 \mathrm{ml}$ of $5 \%$ methanol in $50 \mathrm{~mm}$ carbonate 
buffer ( $\mathrm{pH} 10.0$ ). After washing, the substances were eluted with $0.3 \mathrm{ml}$ of $85 \%$ methanol in $2 \mathrm{~m}$ phosphoric acid.

An aliquot of $20 \mu \mathrm{l}$ eluate was injected into the HPLC

\section{Results and Discussion}

Assay Characteristics A typical chromatogram of the compounds of interest: $p$-OHMAG, $p$-OHMA and MA analyzed by the established method is shown in Fig. 2. The peaks appearing at 22, 48 and 89 min were identified as $p$ OHMAG, $p$-OHMA and MA, respectively. No peak was observed which interfered with the retention times of the compounds of interest.

As shown in Fig. 3, these compounds were eluted within 90 min with excellent separation without any interference by endogenous urinary impurities. A number of different drug free urine samples from healthy subjects were analyzed by the present method, and no significant differences were found among "blank peaks."

Validation As summarized in Table 1, the calibration curves obtained by plotting the peak-height against the concentration of substances showed a good linear correlation at



Fig. 2. Chromatogram of Standard $p$-OHMAG (1), p-OHMA (2) and MA (3)

Chromatographic conditions: column: Inertsil ODS-3 $(150 \times 4.6 \mathrm{~mm}$ i.d., $5 \mu \mathrm{m}$ particle size) equipped with a guard column $(50 \times 4.6 \mathrm{~mm}, 5 \mu \mathrm{m})$; eluent: (A) $10 \mathrm{~mm}$ phosphoric acid-acetonitrile-isopropyl alcohol $(48: 13: 3)$ containing $5 \mathrm{~mm}$ sodium 1-dodecanesulfonate, (B) $10 \mathrm{~mm}$ phosphoric acid-acetonitrile-isopropyl alcohol $(32: 13: 3)$ containing $5 \mathrm{~mm}$ sodium 1-dodecanesulfonate; flow-rate: $1.0 \mathrm{ml} / \mathrm{min} ; 0-25 \mathrm{~min}, 100 \%$

A, after $25 \mathrm{~min}, 100 \% \mathrm{~B}$; detector: $220 \mathrm{~nm}$. Amount spiked $(\mu \mathrm{g} / \mathrm{ml}): p$-OHMAG (8.333), p-OHMA (1.667) and MA (8.333).

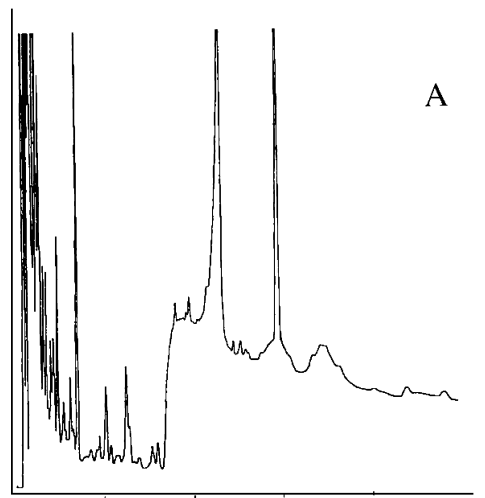

the indicated concentration range with coefficients of determination of $0.9833-0.9930$.

The results of precision and accuracy evaluation for $p$ -

Table 1. Linear Regression Analysis Data

\begin{tabular}{lccc}
\hline \hline & Linear range $(\mu \mathrm{g} / \mathrm{ml})$ & Equation & $r^{2}$ \\
\hline$p$-OHMAG & $0.174-1.389$ & $y=529.28 x+3.3285$ & 0.9930 \\
$p$-OHMA & $0.035-0.556$ & $y=1653.6 x+6.9373$ & 0.9916 \\
MA & $0.174-1.389$ & $y=270.36 x+2.1144$ & 0.9833 \\
\hline
\end{tabular}

Table 2. Precision and Accuracy

\begin{tabular}{|c|c|c|c|c|}
\hline $\begin{array}{l}\text { Concentration } \\
\text { spiked } \\
(\mu \mathrm{g} / \mathrm{ml})\end{array}$ & $\begin{array}{c}\text { Concentration } \\
\text { found } \\
(\mu \mathrm{g} / \mathrm{ml})\end{array}$ & Mean士S.D. & $\begin{array}{l}\text { Precision } \\
\text { RSD } \\
(\%)\end{array}$ & $\begin{array}{c}\text { Accuracy } \\
(\%)\end{array}$ \\
\hline $\begin{array}{c}p \text {-OHMAG } \\
0.347\end{array}$ & $\begin{array}{l}0.334 \\
0.331 \\
0.345\end{array}$ & $0.337 \pm 0.007$ & 2.08 & 97.1 \\
\hline 0.694 & $\begin{array}{l}0.686 \\
0.695 \\
0.757\end{array}$ & $0.713 \pm 0.039$ & 5.47 & 102.7 \\
\hline 1.389 & $\begin{array}{l}1.381 \\
1.377 \\
1.379\end{array}$ & $1.379 \pm 0.002$ & 0.15 & 99.3 \\
\hline $\begin{array}{c}p \text {-OHMA } \\
0.069\end{array}$ & $\begin{array}{l}0.074 \\
0.066 \\
0.068\end{array}$ & $0.069 \pm 0.004$ & 5.80 & 100.0 \\
\hline 0.139 & $\begin{array}{l}0.137 \\
0.135 \\
0.144\end{array}$ & $0.139 \pm 0.005$ & 3.60 & 100.0 \\
\hline 0.278 & $\begin{array}{l}0.288 \\
0.273 \\
0.264\end{array}$ & $0.275 \pm 0.012$ & 4.36 & 98.9 \\
\hline $\begin{array}{l}\text { MA } \\
\quad 0.347\end{array}$ & $\begin{array}{l}0.362 \\
0.373 \\
0.325\end{array}$ & $0.353 \pm 0.025$ & 7.08 & 101.7 \\
\hline 0.694 & $\begin{array}{l}0.717 \\
0.702 \\
0.710\end{array}$ & $0.710 \pm 0.008$ & 1.13 & 102.3 \\
\hline 1.389 & $\begin{array}{l}1.342 \\
1.368 \\
1.350\end{array}$ & $1.353 \pm 0.013$ & 0.96 & 97.4 \\
\hline
\end{tabular}

RSD: relative standard deviation.

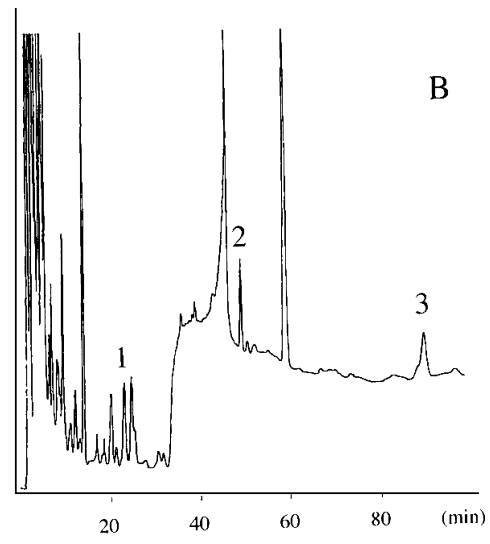

Fig. 3. Chromatograms of (A) Blank Urine, and of (B) Blank Urine Spiked with $p$-OHMAG (1), p-OHMA (2) and MA (3)

Chromatographic conditions: see Fig. 2. Amount spiked ( $\mu \mathrm{g} / \mathrm{ml})$ : $p$-OHMAG (1.667), $p$-OHMA (0.333) and MA (1.667). 
OHMAG, $p$-OHMA and MA are shown in Table 2. As shown in Table 3, recoveries from urine were 97-102\%, 98-99\% and $97-102 \%$ for $p$-OHMAG, $p$-OHMA and MA, respectively. The limits of detection (LOD) for $p-\mathrm{OHMAG}$, $p$-OHMA and MA were found to be $0.139,0.028$ and $0.139 \mu \mathrm{g} / \mathrm{ml}$ (signal-to-noise ratio: 3 ), while the LOQ were $0.174,0.035$ and $0.174 \mu \mathrm{g} / \mathrm{ml}$, respectively.

Stability of the stock solution of substances in distilled water was checked and found to be stable for several months at $4{ }^{\circ} \mathrm{C}$.

Analysis of Autopsy Cases' Urine Sample Typical chromatograms of real case samples are illustrated in Fig. 4A. In the present experiments, a standard addition method was employed (Fig. 4B) instead of a conventional internal standard method as the levels of endogenous urinary impurities of MA abusers were so high that even the clean-up pro-

Table 3. Extraction Recovery

\begin{tabular}{crc}
\hline \hline $\begin{array}{c}\text { Concentration } \\
(\mu \mathrm{g} / \mathrm{ml})\end{array}$ & $\begin{array}{c}\text { Recovery } \\
(\%, \text { mean } \pm \mathrm{SD})\end{array}$ & $\begin{array}{c}\mathrm{RSD} \\
(\%)\end{array}$ \\
\hline$p$-OHMAG & & \\
0.347 & $97.0 \pm 2.10$ & 2.16 \\
0.694 & $102.9 \pm 5.41$ & 5.26 \\
1.389 & $99.3 \pm 0.15$ & 0.15 \\
$p$-OHMA & & \\
0.069 & $100.5 \pm 5.98$ & 5.95 \\
0.139 & $99.8 \pm 3.40$ & 3.41 \\
0.278 & $98.9 \pm 4.35$ & 4.40 \\
MA & & \\
0.347 & $101.8 \pm 7.22$ & 7.09 \\
0.694 & $102.3 \pm 1.05$ & 1.03 \\
1.389 & $97.4 \pm 0.97$ & 1.00 \\
\hline
\end{tabular}

RSD: relative standard deviation.

Table 4. Quantitative Analysis of Urine Samples Collected from Autopsy Cases

\begin{tabular}{lccc}
\hline \hline & $\begin{array}{c}p \text {-OHMAG } \\
(\mu \mathrm{g} / \mathrm{ml})\end{array}$ & $\begin{array}{c}p \text {-OHMA } \\
(\mu \mathrm{g} / \mathrm{ml})\end{array}$ & $\begin{array}{c}\text { MA } \\
(\mu \mathrm{g} / \mathrm{ml})\end{array}$ \\
\hline Case 1 & 1.707 & 0.446 & 12.326 \\
Case 2 & 1.595 & 0.408 & 15.925 \\
Case 3 & 0.898 & 0.426 & 4.011 \\
\hline
\end{tabular}

Case 1: 23-year-old male; Case 2: 29-year-old male; Case 3: 42-year-old male.
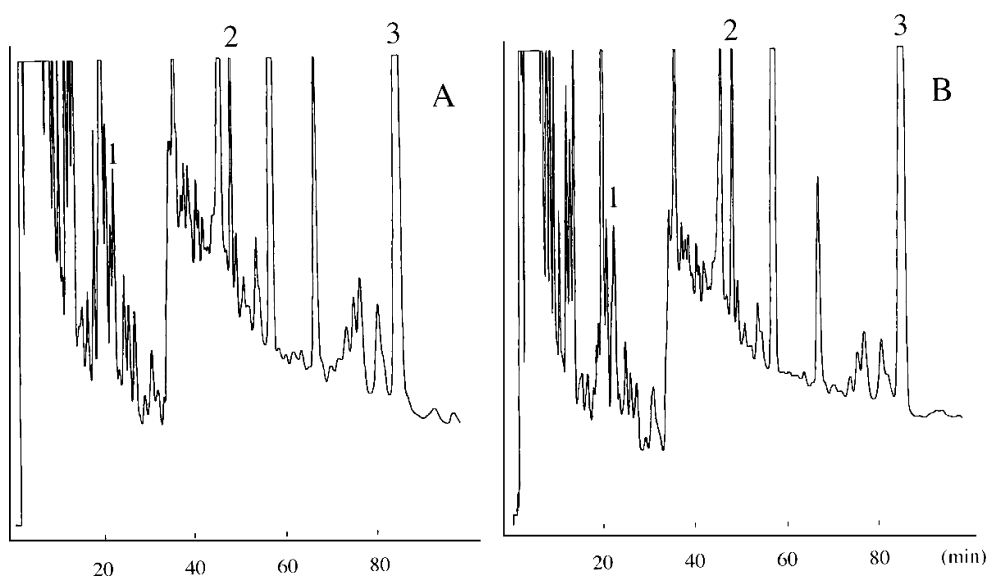

Fig. 4. Chromatograms Obtained from a Urine Sample of an MA Abuser, Case 1 (A) and Standard Addition Technique (B)

Peaks: 1, p-OHMAG; 2, p-OHMA; 3, MA. Chromatographic conditions: see Fig. 2. Amount spiked ( $\mu$ g/ml): p-OHMAG (2.778), $p$-OHMA (0.556) and MA (2.778). cedures developed in this investigation were unable to completely remove them. Figure 4B shows a chromatogram of a mixture of $0.1 \mathrm{ml}$ of the extract from an abuser's urine and $0.2 \mathrm{ml}$ of the extract from spiked urine.

Urine samples of three MA abusers were tested to determine MA and its metabolites by the proposed method (Table 4 ). In Cases 1 and 2, the ratios of MA to total $p$-OHMA were almost equal to those reported in the literature, ${ }^{3)}$ while in Case 3, the level of total $p$-OHMA was found to be about twice as high as the expected level of a total $p$-OHMA calculated from the level of MA found in the present experiment. It is our assumption that these results may be due to an individual variation in metabolism and/or different causes of death.

\section{Conclusions}

A simple and reproducible method for the simultaneous determination of MA and its metabolites $p$-OHMA and $p$ OHMAG in urine was established employing the combination of a solid-phase extraction and reversed-phase HPLC. This method was successfully evaluated in terms of linearity, precision, LOD and LOQ.

This is the first report of the presence of $p$-OHMAG being detected using HPLC in the urine sample of an MA abuser.

Acknowledgement The authors are grateful to Dr. Tatsuya Murai for his kind advice in conduct of this study.

\section{References}

1) Sakai T., Niwaguchi T., Murata T., Xenobiotica, 12, 233-239 (1982).

2) Hara K., Kageura M., Hieda Y., Kashimura S., Z. Rechtsmed., 100, 231-236 (1988).

3) Caldwell J., Dring L. G., Williams R. T., Biochem. J., 129, 11-22 (1972).

4) Cheung S., Nolte H., Otton S. V., Tyndale R. F., Wu P. H., Sellers E. M., J. Chromatogr. B, 690, 77-87 (1997).

5) Hayakawa K., Miyoshi Y., Kurimoto H., Matsushima Y., Takayama N., Tanaka S., Miyazaki M., Biol. Pharm. Bull., 16, 817-821 (1993).

6) Sakai T., Niwaguchi T., Kimura R., Murata T., Xenobiotica, 13, 715724 (1983).

7) Sakai T., Niwaguchi T., Kimura R., Murata T., Xenobiotica, 15, $31-$ 40 (1985).

8) Shimosato K., Tomita M., Ijiri I., Arch. Toxicol., 59, 135-140 (1986).

9) Nakajima R., Ono M., Aiso S., Akita H., Chem. Pharm. Bull., 53, 684-687 (2005). 